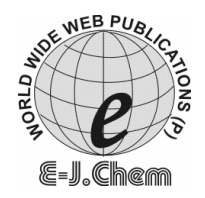

http://www.e-journals.net
ISSN: 0973-4945; CODEN ECJHAO

E-Journal of Chemistry

2009, 6(2), 481-488

\title{
Simulation of Few Bifurcation Phase Diagrams of Belousov-Zhabotinsky Reaction with Eleven Variable Chaotic Model in CSTR
}

\author{
B. SWATHI and V.R. KULKARNI* \\ Department of Chemistry, \\ Gulbarga University, Gulbarga-585 106, Karnataka, India. \\ swathi_81@rediffmail.com
}

Received 24 November 2007; Revised 21 July 2008; Accepted 10 September 2008

\begin{abstract}
Simulation of the Gyorgyi, Rempe and Field eleven variable chaotic model in CSTR [Continuously Stirred Tank Reactor] is performed with respect to the concentrations of malonic acid and [Ce(III)]. These simulation studies show steady state, periodic and non-periodic regions. These studies have been presented as two variable bifurcation phase diagrams. We also have observed the bursting phenomenon under different set of constraints. We have given much importance on computer simulation work but not included the experimental methods in this paper.
\end{abstract}

Keywords: Belousov-Zhabotinsky reaction, Oscillating reactions, Chaotic behavior, Bifurcation diagrams, Bursting phenomenon.

\section{Introduction}

The classical Belousov-Zhabotinsky (BZ) reaction ${ }^{1,2}$ is basically a chemical reaction which shows oscillations in the concentrations of few intermediates under certain conditions. It is a prototype example showing non-linear chemical dynamics. It is the simultaneous oxidation and bromination of a suitable organic substrate by acidic bromate in the presence of a metal catalyst. Studies of BZ reaction in well stirred flow reactors have revealed much more than simple periodic oscillations; a rich variety of more complex dynamical behaviors such as complex periodicity, multistability hysteresis and even chaos has been found both in experiments and in simulations. In this reaction, the concentrations of catalyst and / or intermediate species undergo oscillations in time and space. The behavior is driven by the Gibbs free energy decrease of an overall chemical reaction occurring far from equilibrium. A rigorous mechanism for the oscillatory behavior in the BZ reaction was given by Field, Koros and Noyes $^{3}$ (FKN) in 1972. Later several authors have reported the behavior experimentally under closed and open system conditions. Schmitz et at have reported these a periodic oscillations experimentally under CSTR conditions in 1977. Since then, several experimental 
studies have been made at low as well as at high flow rates. For the better understanding of BZCSTR chaos, many models came in to existence. An eleven variable model was extracted from the FKN mechanism. Further 9, 7, 4 and 3 variable models were obtained ${ }^{5}$. All models with four or more variables reproduce the major features of the experimentally observed at low flow rate conditions. Hence in our present simulation work, we focus our attention on an 11 variable model proposed by Gyorgyi et $a l^{6}$ to account both for periodic \& non-periodic behaviors. Their study was aimed to model behavior with respect to flow rate only. In this context a detailed simulation of this model has been done to include various input concentrations.

\section{Reaction mechanism and computation method}

In a CSTR study, one or more fluid reagents are introduced in to a tank reactor equipped with an impeller while the reactor effluent is removed. The impeller stirs the reagents to ensure proper mixing. Simply dividing the volume of the tank by average volumetric flow rate through the tank gives the residence time since the approach is to report the data in terms of inverse of residence time. Study of the dynamics in CSTR could be made by initially having a batch system in the reactor and this batch system could be converted to the flow system by starting the flows. Another way of studying the dynamics is starting with an empty reactor vessel and studying the dynamics after filling the CSTR. During simulations these practical considerations are not necessary. The volume of the reactor is irrelevant as the flow rate is considered in terms of inverse of residence time. Hence the simulation is done by considering the flow rate, initial concentrations of various species and inflow concentration of major reactants.

The overall $\mathrm{BZ}$ reaction is given by

$$
3 \mathrm{CH}_{2}(\mathrm{COOH})_{2}+2 \mathrm{BrO}_{3}^{-}+2 \mathrm{H}^{+} \rightarrow 2 \mathrm{BrCH}(\mathrm{COOH})_{2}+4 \mathrm{H}_{2} \mathrm{O}+3 \mathrm{CO}_{2}
$$

Table 1 describes the eleven variable GRF chaotic mechanisms consisting of 11 chemical species and 15 reaction steps of which 1, 3, 5 and 6 are reversible. The relevant rate constants are given in Table 2. We have taken this 11- variable model and studied the behaviors of various chemical species like MA \& [Ce(III)]. The kinetics of this system in batch can be described by a system of non-linear first order differential equations obtained by applying law of mass action to each step. Such a system of differential equations ${ }^{7}$ can be denote by

Table 1. Eleven variable GRF chaotic mechanisms.

\begin{tabular}{|c|c|c|c|}
\hline 1 & $\mathrm{HOBr}+\mathrm{Br}^{-}+\left\{\mathrm{H}^{+}\right\}$ & $\rightleftharpoons$ & $\mathrm{Br}_{2}+\left\{\mathrm{H}_{2} \mathrm{O}\right\}$ \\
\hline 2 & $\mathrm{Br}^{-}+\mathrm{HBrO}_{2}+\left\{\mathrm{H}^{+}\right\}$ & $\rightarrow$ & $2 \mathrm{HOBr}$ \\
\hline 3 & $\mathrm{Br}^{-}+\left\{\mathrm{BrO}_{3}\right\}+\left\{2 \mathrm{H}^{+}\right\}$ & $\rightleftharpoons$ & $\mathrm{HOBr}+\mathrm{HBrO}_{2}$ \\
\hline 4 & $2 \mathrm{HBrO}_{2}$ & $\rightarrow$ & $\left\{\mathrm{BrO}_{3}\right\}+\mathrm{HOBr}+\left\{\mathrm{H}^{+}\right\}$ \\
\hline 5 & $\left\{\mathrm{BrO}_{3}\right\}+\mathrm{HBrO}_{2}+\left\{\mathrm{H}^{+}\right\}$ & $\rightleftharpoons$ & $2 \mathrm{BrO}_{2} *+\left\{\mathrm{H}_{2} \mathrm{O}\right\}$ \\
\hline 6 & $\mathrm{Ce}^{3+}+\mathrm{BrO}_{2} *+\left\{\mathrm{H}^{+}\right\}$ & $\rightleftharpoons$ & $\mathrm{HBrO}_{2}+\mathrm{Ce}^{4+}$ \\
\hline 7 & $\mathrm{MA}+\mathrm{Br}_{2}$ & $\rightarrow$ & $\mathrm{BrMA}+\mathrm{Br}^{-}+\left\{\mathrm{H}^{+}\right\}$ \\
\hline 8 & $\mathrm{MA}+\mathrm{HOBr}$ & $\rightarrow$ & $\mathrm{BrMA}+\left\{\mathrm{H}_{2} \mathrm{O}\right\}$ \\
\hline 9 & $\mathrm{MA}+\mathrm{Ce}^{4+}$ & $\rightarrow$ & $\mathrm{MA}^{*}+\mathrm{Ce}^{3+}\left\{\mathrm{H}^{+}\right\}$ \\
\hline 10 & $\mathrm{BrMA}+\mathrm{Ce}^{4+}$ & $\rightarrow$ & $\mathrm{Ce}^{3+}+\mathrm{Br}^{-}+[$Products $]$ \\
\hline 11 & $\mathrm{MA}^{*}+\mathrm{HOBr}$ & $\rightarrow$ & $\mathrm{MA}+\mathrm{Br}^{-}+[$Products $]$ \\
\hline 12 & $\mathrm{MA}^{*}+\mathrm{Br}_{2}$ & $\rightarrow$ & $\mathrm{BrMA}+\mathrm{Br}^{*}$ \\
\hline 13 & $\mathrm{MA}^{*}+\mathrm{HOBr}$ & $\rightarrow$ & $\mathrm{Br}^{*}+[$ Products $]$ \\
\hline 14 & $2 \mathrm{MA}^{*}$ & $\rightarrow$ & MA + [Products $]$ \\
\hline 15 & $\mathrm{Br}^{*}+\mathrm{MA}$ & $\rightarrow$ & $\mathrm{Br}^{-}+\mathrm{MA}^{*}+[$ Products $]$ \\
\hline
\end{tabular}

Note: $*$ indicates the radical species. 
Table 2. Rate constants of 15 reaction steps.

\begin{tabular}{ll}
\hline $\mathrm{k}_{1}=6.0 \mathrm{e}^{+8} \mathrm{M}^{-1} \mathrm{~S}^{-1}$ & \\
$\mathrm{k}_{-1}=2.0 \mathrm{~s}^{-1}$ & $\mathrm{k}_{7}=40.0 \mathrm{M}^{-1} \mathrm{~s}^{-1}$ \\
$\mathrm{k}_{2}=5.2 \mathrm{e}^{+5} \mathrm{M}^{-1} \mathrm{~s}^{-1}$ & $\mathrm{k}_{8}=8.2 \mathrm{M}^{-1} \mathrm{~s}^{-1}$ \\
$\mathrm{k}_{3}=0.01352 \mathrm{~s}^{-1}$ & $\mathrm{k}_{9}=0.3 \mathrm{M}^{-1} \mathrm{~s}^{-1}$ \\
$\mathrm{k}_{-3}=3.2 \mathrm{M}^{-1} \mathrm{~s}^{-1}$ & $\mathrm{k}_{10}=30.0 \mathrm{M}^{-1} \mathrm{~s}^{-1}$ \\
$\mathrm{k}_{4}=3.0 \mathrm{e}^{+3} \mathrm{M}^{-1} \mathrm{~s}^{-1}$ & $\mathrm{k}_{11}=2.4 \mathrm{e}^{+4} \mathrm{M}^{-1} \mathrm{~s}^{-1}$ \\
$\mathrm{k}_{5}=0.858 \mathrm{~s}^{-1}$ & $\mathrm{k}_{12}=1.5 \mathrm{e}^{+8} \mathrm{M}^{-1} \mathrm{~s}^{-1}$ \\
$\mathrm{k}_{-5}=4.2 \mathrm{e}^{+7} \mathrm{M}^{-1} \mathrm{~s}^{-1}$ & $\mathrm{k}_{13}=1.0 \mathrm{e}^{+7} \mathrm{M}^{-1} \mathrm{~s}^{-1}$ \\
\hline
\end{tabular}

The initial concentrations of all the variables at time zero are considered as $1 \times 10^{-10} \mathrm{M}$. The inflow concentrations chosen as standard were $\left[\mathrm{H}_{2} \mathrm{O}\right]=55 \mathrm{M},\left[\mathrm{BrO}_{3}{ }^{-}\right]=0.1 \mathrm{M}$ and $\left[\mathrm{H}^{+}\right]=0.26 \mathrm{M}$, included in the appropriate rate constants. Mixed feed concentrations: Malonic acid $=0.25 \mathrm{~m}$ and $\mathrm{Ce}^{3+}=0.0008333 \mathrm{M}$.

$$
\mathrm{dC}_{\mathrm{i}} / \mathrm{dt}=\Sigma_{\mathrm{j}} \alpha_{\mathrm{ij}} \mathrm{R}_{\mathrm{j}}
$$

Where, $C_{i}$ is the concentration of $i^{\text {th }}$ species in the reactor at time $t, \alpha_{i j}$ is the stoichiometric coefficient of the $i^{\text {th }}$ species in the reaction $\mathrm{j}$, which proceeds at the rate is calculated from mass action kinetics. The activity of $\mathrm{H}_{2} \mathrm{O}$ is taken as unity. This set of equations gets modified in a CSTR by the flow terms as follows.

$$
\mathrm{dC}_{\mathrm{i}} / \mathrm{dt}=\Sigma_{\mathrm{j}} \alpha_{\mathrm{ij}} \mathrm{R}_{\mathrm{j}}+\mathrm{k}_{0}\left(\mathrm{C}_{\mathrm{i}, 0}-\mathrm{C}_{\mathrm{i}}\right)
$$

Where, $\mathrm{C}_{\mathrm{i}, 0}$ is the inflow concentration of species $i$.. The dynamics of the system could be obtained by integration of this set of differential equations. There are various soft wares are available to solve such problems. We have software called Simulate with us, which incorporates the powerful Rosenbrock's integrator of stiff differential systems. Simulate sets up its own differential equations and result is provided as integrated values, when appropriate mechanism, initial concentrations and input concentrations are given. The error tolerance of integrator used is $10^{-7}$, initial step size is $10^{-8}$ and maximum step size is 2.0. In the CSTR mode, there are two important initial conditions, namely, the initial concentrations of various species in the reactor and inflow concentration, namely the concentrations of various species which would be obtained in the reactor due to the flows. The initial concentration of all the species in the reactor at time zero is considered as $1 \times 10^{-10} \mathrm{M}$. The inflow concentrations chosen are $\left[\mathrm{H}_{2} \mathrm{O}\right]=55 \mathrm{M},\left[\mathrm{BrO}_{3}{ }^{-}\right]=0.1 \mathrm{M},\left[\mathrm{H}^{+}\right]=0.26 \mathrm{M},[\mathrm{MA}]=$ $0.25 \mathrm{M}$ and $\left[\mathrm{Ce}^{3+}\right]=0.0008333 \mathrm{M}$. And the flow rate taken for all studies is $3.071 \times 10^{-4} \mathrm{~s}^{-1}$. This set of inflow concentrations are considered as the standard for determining the behavior of the system with respect to variables.

\section{Results and Discussion}

Gyorgyi et al simulated the 11 variable models at the flow rates ranging from $1.00 \times 10^{-4} \mathrm{~s}^{-1}$ to $3.25 \times 10^{-4} \mathrm{~s}^{-1}$. They obtained small amplitude oscillations at lower flow rates $\left(1.00 \times 10^{-4} \mathrm{~s}^{-1}\right)$ and large amplitude oscillations at higher flow rates. $\left(3.25 \times 10^{-4} \mathrm{~s}^{-1}\right)$ In between these two flow rates they observed period-2, period-4 \& even chaos. They also have found bistability in the neighborhood of some flow rates. $\left(1.25-1.50 \times 10^{-4} \mathrm{~s}^{-1}\right.$ and $\left.2.70 \times 10^{-4} \mathrm{~s}^{-1}\right)$ Thus at these flow rates, they found periodic oscillations while the flow is increasing and on the other hand they found nonperiodic oscillations when the flow is decreasing during the reverse path. We have also reproduced their results. In their paper they have reported only the effect of flow rate on chaotic eleven variable models. In addition to their work, we have done simulations with respect to various input concentrations of other chemical species and also we have given the behavior of all the chemical species present in the model. We have chosen a flow rate $3.071 \times 10^{-4} \mathrm{~s}^{-1}$ for our work. 
The eleven variable model presented in the Table 1 has been analyzed with respect to the variations in concentrations of variables. The above mentioned flow rate has been found suitable for the study of the effect of inflow concentrations. The range of inflow concentrations we have studied were $[\mathrm{MA}]_{0}=0.001 \mathrm{M}-0.2 \mathrm{M},[\mathrm{Ce}(\mathrm{III})]_{0}=0.0005-0.2 \mathrm{M}$. Figure 1 indicates the behavior of the various chemical species at the standard inflow concentrations and flow rate conditions. Oscillations in concentrations of appreciable amplitude are observed for most of the intermediates. The temporal behavior of various species, i.e., the concentrations at few extreme values indicated as 1, 2, 3, 4 in Figure 1. Similar types of large amplitude oscillations were observed for all the species except $\mathrm{Br}_{2}$ and $\mathrm{Br}^{-}$. We observed small amplitude oscillations for both these species. And the maximum in $\left[\mathrm{Br}^{-}\right]$coincides with the minimum in $\left[\mathrm{Ce}^{4+}\right]$. First peak appears at $300 \mathrm{~s}$. After a long period second peak appears at $3500 \mathrm{~s}$ for almost all species. And these oscillations are very quick, i.e., of high frequency.

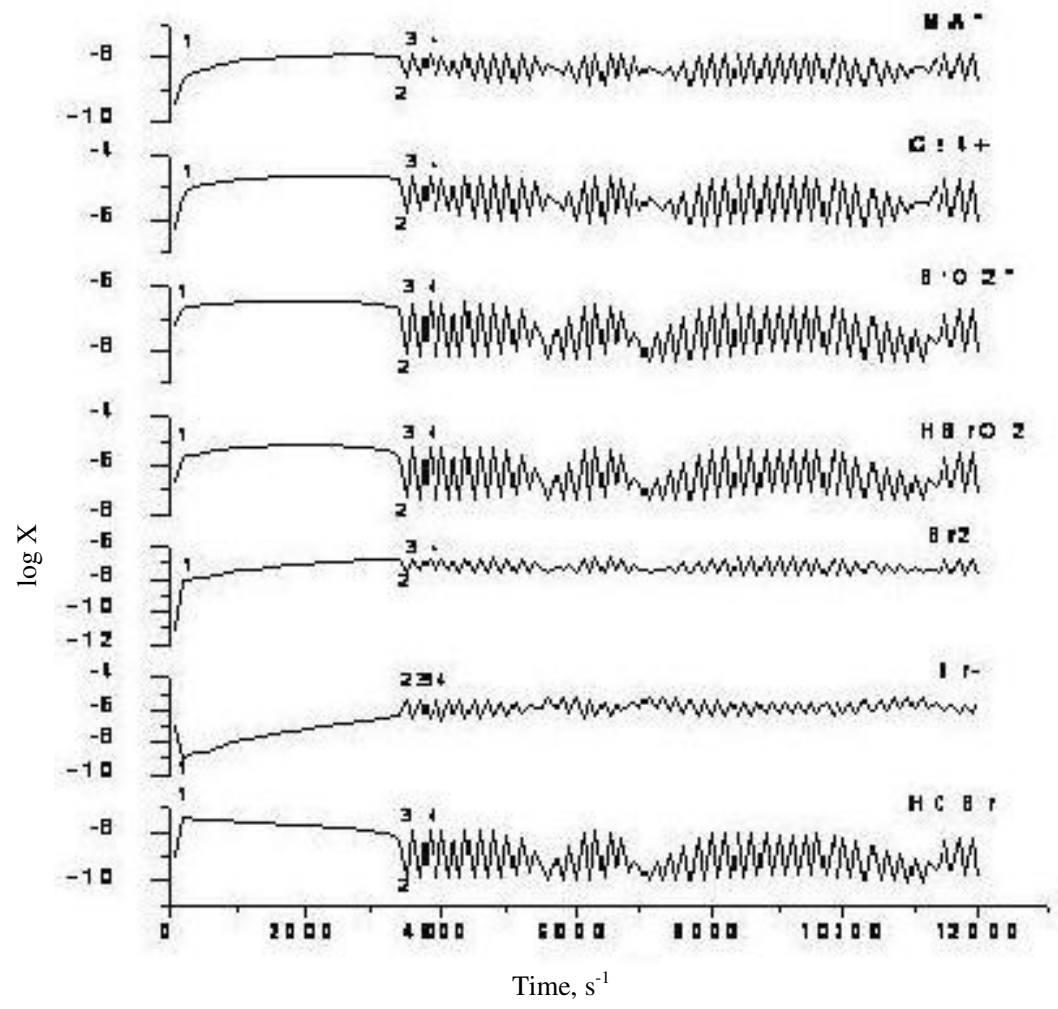

Figure 1. Simulated plots of oscillations of different species at a flow rate of $3.071 \times 10^{-4} \mathrm{~s}^{-1}$ with initial concentrations of all species at $1 \times 10^{-10} \mathrm{~s}^{-1}$. The inflow concentrations $\left[\mathrm{H}_{2} \mathrm{O}\right]=55$ $\mathrm{M},\left[\mathrm{BrO}_{3}{ }^{-}\right]=0.1 \mathrm{M}$ and $\left[\mathrm{H}^{+}\right]=0.26 \mathrm{M}$.

\section{Effect of Malonic acid}

$[\mathrm{MA}]_{0}$ was varied in the range $0.001 \mathrm{M}-0.2 \mathrm{M}$ and other constraints were as that of the standard. The resulting traces of $[\mathrm{Ce}(\mathrm{IV})]$ are indicated in Figure 2. The oscillations start after a transient period of $2500 \mathrm{~s}$.

(a) For $[\mathrm{MA}]=0.001 \mathrm{M}$, periodic oscillations were observed. 
(b) When $[\mathrm{MA}]=0.002-0.04 \mathrm{M}$, similar type of oscillations were observed as the induction period remains same, number of cycles increases as the concentration of MA increases.

(c) When $[\mathrm{MA}]=0.06-0.2 \mathrm{M}$ a modulated type of oscillations were observed, in which nearly identical pulses of several large amplitude oscillations are separated by some small amplitude oscillations.

(d) Above $[\mathrm{MA}]=0.3 \mathrm{M}$, no oscillations were observed.

The amplitudes of the oscillations don't change much with the change in concentration. On the other hand the frequency of oscillations increases as the concentration of MA is increased to a higher level.

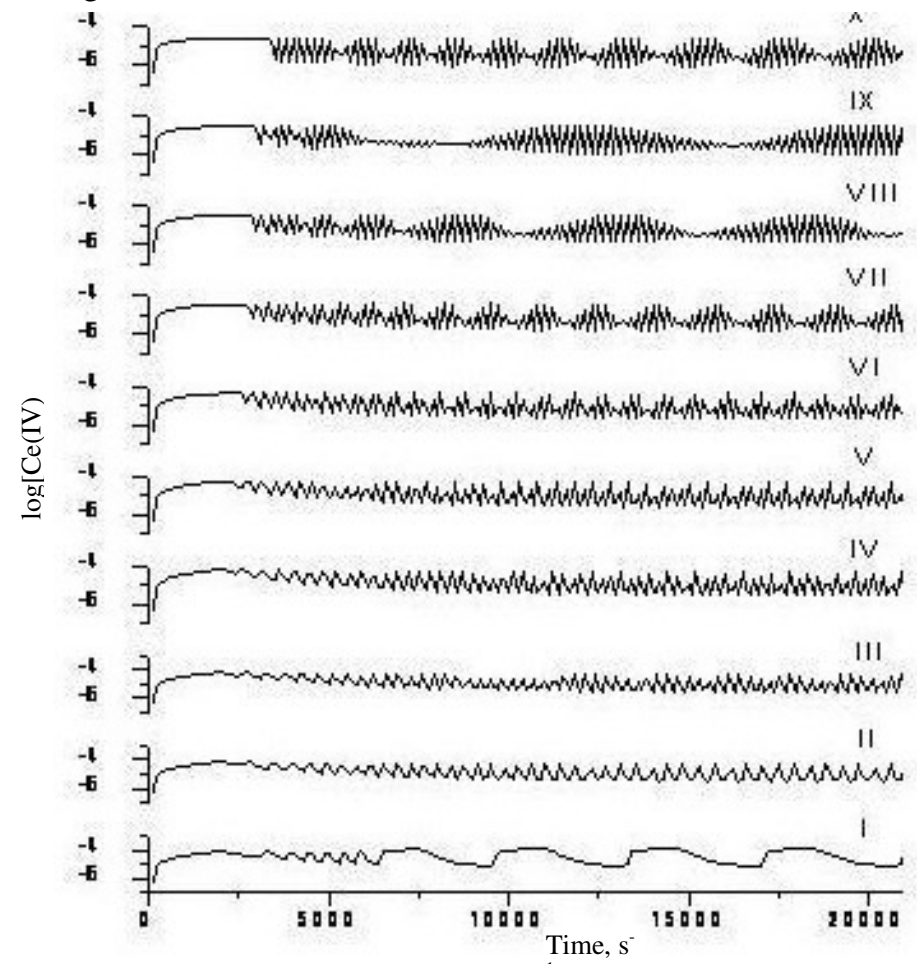

Figure 2. Dependence of oscillatory characteristics on malonic acid concentrations.

System: $\left[\mathrm{H}_{2} \mathrm{O}\right]=55 \mathrm{M},\left[\mathrm{BrO}_{3}{ }^{-}\right]=0.1 \mathrm{M}$ and $\left[\mathrm{H}^{+}\right]=0.26 \mathrm{M}$ and $[\mathrm{MA}]_{0}$ : (I) $=0.001 \mathrm{M},(\mathrm{II})=0.002 \mathrm{M},(\mathrm{III})=0.004$ $\mathrm{M},(\mathrm{IV})=0.008 \mathrm{M},(\mathrm{V})=0.02 \mathrm{M},(\mathrm{VI})=0.04 \mathrm{M},(\mathrm{VII})=0.06 \mathrm{M},(\mathrm{VIII})=0.08 \mathrm{M},(\mathrm{IX})=0.1 \mathrm{M},(\mathrm{X})=0.2 \mathrm{M}$.

Effect of [Ce(III)]

$[\mathrm{Ce}(\mathrm{III})]_{0}$ was varied in the range $0.0005-0.2 \mathrm{M}$. Figure 3 represents the traces of $[\mathrm{Ce}(\mathrm{IV})]$ at the indicated inflow concentrations and flow rate.

(a) For $[\mathrm{Ce}(\mathrm{III})]_{0}=(0.0005-0.001 \mathrm{M})$ oscillations appear to be modulated. Several bunch of large amplitude oscillations are separated by one or two small amplitude oscillations. No bunch in the series contains same number of oscillations.

(b) For $[\mathrm{Ce}(\mathrm{III})]_{0}=0.005 \mathrm{M}$ and $0.01 \mathrm{M}$, non-periodic oscillations were observed in which, large \& small amplitude oscillations were irregularly obtained. As we increase the concentration of $[\mathrm{Ce}(\mathrm{III})]_{0}$ further, the frequency of oscillations decreases.

(c) Above $[\mathrm{Ce}(\mathrm{III})]_{0}=0.3 \mathrm{M}$ no oscillations were observed. 


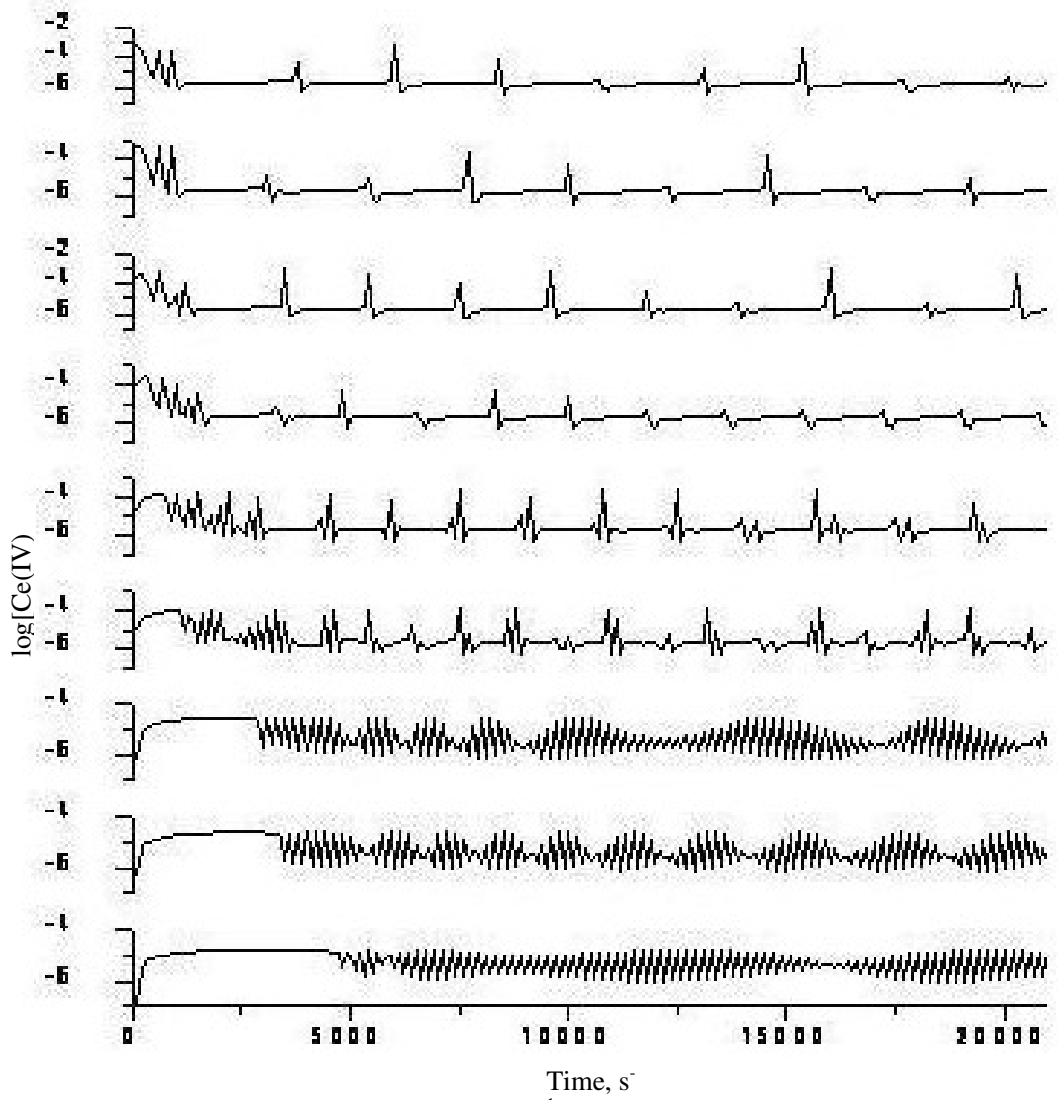

Figure 3. Simulated plots of oscillations in $[\mathrm{Ce}(\mathrm{IV})]$ at different inflow concentrations of $\mathrm{Ce}(\mathrm{III})$ with initial concentrations of various species at $1 \times 10^{-10} \mathrm{M}$; Inflow concentrations of $\mathrm{Ce}(\mathrm{III})$ are (I) $=0.0005 \mathrm{M}$, (II) $=0.0008 \mathrm{M},(\mathrm{III})=0.001 \mathrm{M},(\mathrm{IV})=0.005 \mathrm{M},(\mathrm{V})=0.01 \mathrm{M}$ $(\mathrm{VI})=0.05 \mathrm{M},(\mathrm{VII})=0.1 \mathrm{M},(\mathrm{VIII})=0.2 \mathrm{M},(\mathrm{IX})=0.3$.

The induction period goes on decreasing as we increase the concentration of cerium. and the period of oscillations increases. The amplitude increases at the lower values of $[\mathrm{Ce}(\mathrm{III})]_{0} \&$ remains nearly unchanged as $[\mathrm{Ce}(\mathrm{III})]_{0}$ is increased at higher ranges of $[\mathrm{Ce}(\mathrm{III})]_{0}$. Thus for higher range of $[\mathrm{Ce}(\mathrm{III})]_{0}$ the period is increasing while the amplitude remains the same for further increase in $[\mathrm{Ce}(\mathrm{III})]_{0}$.

\section{Bursting and Composed oscillations}

Bursting and Composed oscillations have been observed by almost all experimentalists working on oscillating reactions in $\mathrm{CSTR}^{8}$. In this phenomenon, bursts of large amplitude oscillations are separated by periods of quiescence or small amplitude oscillations, which appear periodically over a long period. As the control parameter is varied the number of oscillations per burst increases or decreases until a bifurcation to the steady state or some other form of oscillatory behavior occurs. In our present study we have observed these bursts at the flow rate of $3.071 \times 10^{-4} \mathrm{~s}^{-1}$ and the input concentrations of MA and $\mathrm{Ce}$ (III) are $0.02 \mathrm{M} \& 0.004 \mathrm{M}$ respectively. These types of bursts are represented in the Figure 4. 


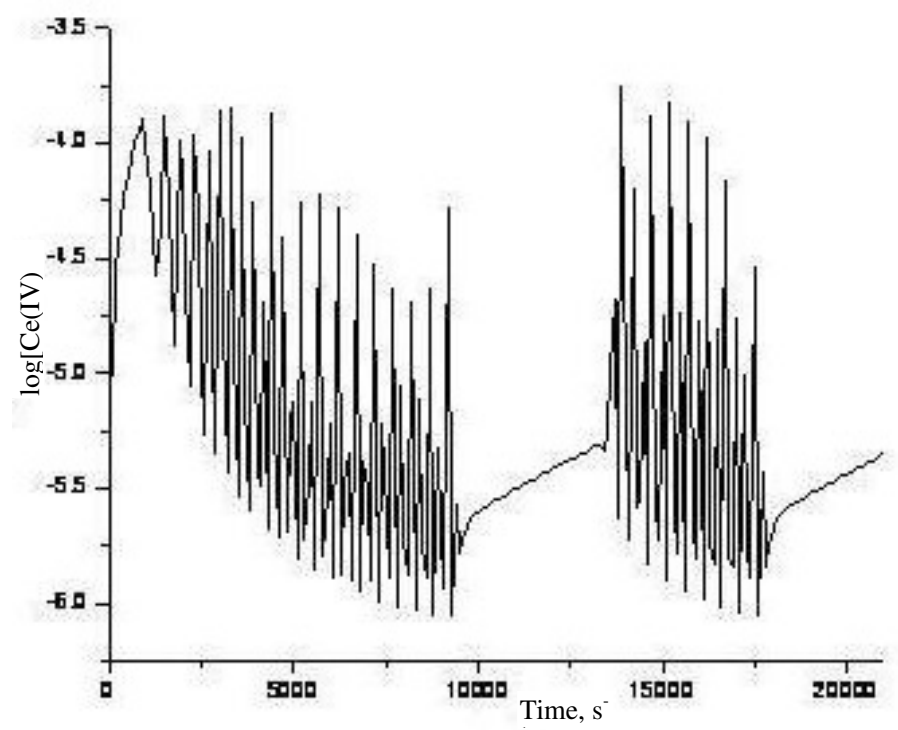

Figure 4. Bursting oscillations observed in the chaotic model of the $\mathrm{BZ}$ reaction with $\left[\mathrm{H}_{2} \mathrm{O}\right]$ $=55 \mathrm{M},\left[\mathrm{BrO}_{3}{ }^{-}\right]=0.1 \mathrm{M} ;\left[\mathrm{H}^{+}\right]=0.26 \mathrm{M} ;[\mathrm{MA}]=0.02 \mathrm{M} ;[\mathrm{Ce}(\mathrm{IIII})]=0.004 \mathrm{M}$ at a flow rate of $3.071 \times 10^{-4} \mathrm{~s}^{-1}$

\section{Bifurcation studies}

A bifurcation phase diagram is useful in describing the dynamical behavior of chemical systems. The results of many time series can be shown in single plot whose axes are the two or some times three constraint variables of interest. Each point on the plot indicates what kind of state or states (steady, oscillatory or chaotic) is observed by the lines separating different regions indicating bifurcation where the nature of the solution changes at that particular set of parameter. Two parameter phase plots were constructed by increasing and decreasing one of the parameters under considerations (all other parameters being fixed). The results obtained have been presented as two parameter phase diagrams $^{9,10}$. However, presently we have performed simulations of the system at various (high/low) fixed values of the test constraints without involving the hysteresis process. The observations thus obtained are presented in Figure (5) showing oscillatory \& nonperiodic regions. The bifurcation parameters chosen are $\left[\mathrm{Ce}^{3+}\right]_{0}-[\mathrm{MA}]_{0}$ at fixed inflow concentrations of $\left[\mathrm{H}_{2} \mathrm{O}\right]=55 \mathrm{M},\left[\mathrm{BrO}_{3}\right]=0.1 \mathrm{M}$ and $\left[\mathrm{H}^{+}\right]=0.26 \mathrm{M}$ and flow rate is taken as $3.071 \times 10^{-4} \mathrm{~s}^{-1}$. The time of observation is of the order of $15000 \mathrm{~s}$. The only parameters varied were the concentrations of MA \& Ce(III). The phase diagram was obtained by maintaining a constant flow rate $\left(3.071 \times 10^{-4} \mathrm{~s}^{-1}\right)$ while using different combinations of MA $\& \mathrm{Ce}(\mathrm{III})$ concentrations.

The $\left[\mathrm{Ce}^{3+}\right]_{0}-[\text { Malonic acid }]_{0}$ phase diagram is indicated in Figure 5. Both $\left[\mathrm{Ce}^{3+}\right]_{0}$ and [Malonic acid] $]_{0}$ were varied from an initial value of $0.0001 \mathrm{M}$ to $0.1 \mathrm{M}$ and back again. No oscillations were observed at the lower concentrations of Oxalic acid. Periodic oscillations were observed at the higher concentrations of malonic acid. Chaos is observed at much higher concentrations of acid. No bistability was observed at this flow rate. At the higher concentrations of MA we have not found any oscillations. We observed steady state behavior. 


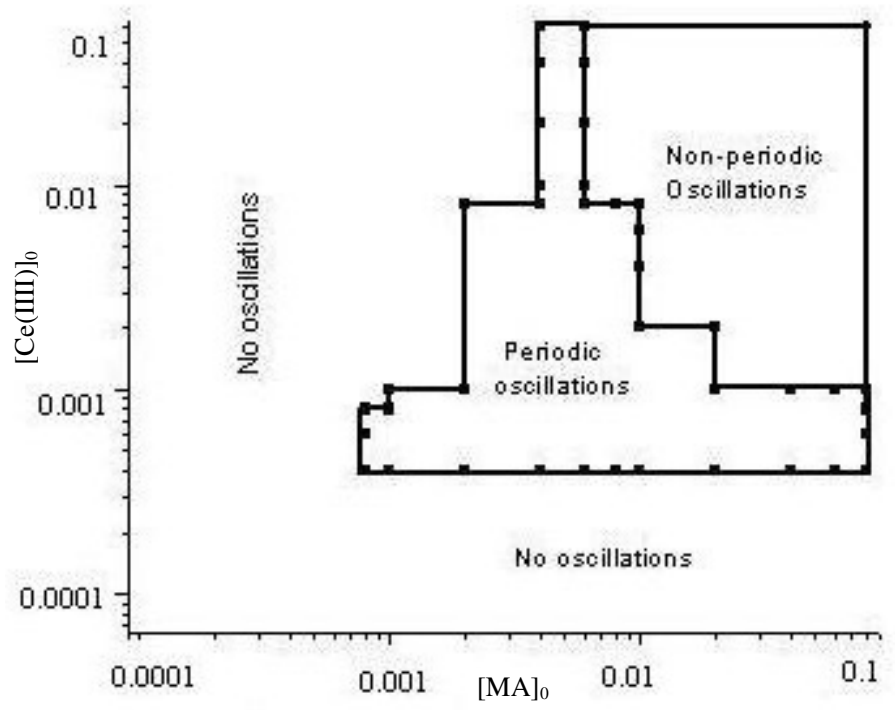

Figure 5. Bifurcation phase diagram of $[\mathrm{MA}]_{0}$ and $[\mathrm{Ce}(\mathrm{IIII})]_{0}$.

\section{Acknowledgement}

The authors are thankful to UGC, New Delhi for supporting this work. The authors thank Prof. S.D.Angadi, Chairman, Department of Chemistry, Gulbarga University, Gulbarga for providing facilities.

\section{References}

1. Biodis J, Field R J, Oscillations and Traveling waves in Chemical systems; Field R J Burger M Eda; Wiley-Interscience, Newyork, 1985.

2. Gray P and Scott S K, Chemical Oscillations and Instabilities; Non-linear Chemical Kinetics; Claredon Press: Oxford, U.K., 1990.

3. Field J, Koros E and Noyes R M, J Am Chem Soc., 1972, 94, 8649.

4. Scmitz R A, Grazini K R and Hudson J L, J Phys Chem., 1977, 67, 3040.

5. Gyorgyi L and Field J, J Phys Chem., 1991, 95, 6594-6602.

6. Gyorgyi L, Rempe S and Field J, J Phys Chem., 1991, 95, 3159-3165.

7. Basavaraja C, Vishnuvardhan T K and Kulkarni V R, J Indian Chem Soc., 2003, 100-105.

8. Bar-Eli K and Noyes R M, J Phys Chem.,1988, 88, 3636-54.

9. Field J and Foresterling H D, J Phys Chem., 1986, 90, 5400.

10. Gaspar V and Galambosi P, J Phys Chem., 1986, 90, 2222-2226.

11. Rastogi R P and Misra G P, J Phys Chem., 1987, 91, 3007-3010. 


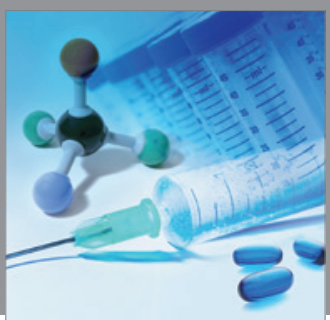

International Journal of

Medicinal Chemistry

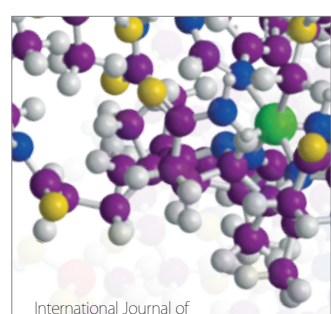

Carbohydrate Chemistry

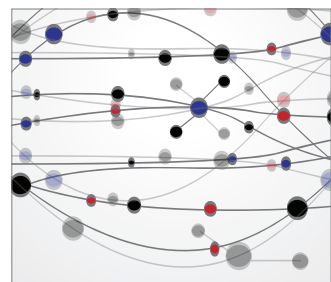

The Scientific World Journal
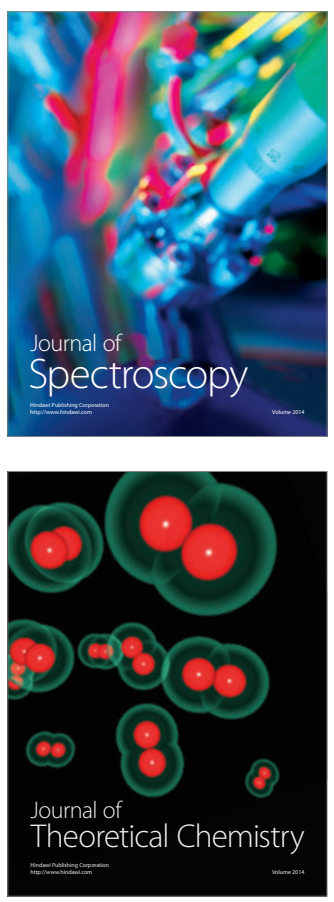
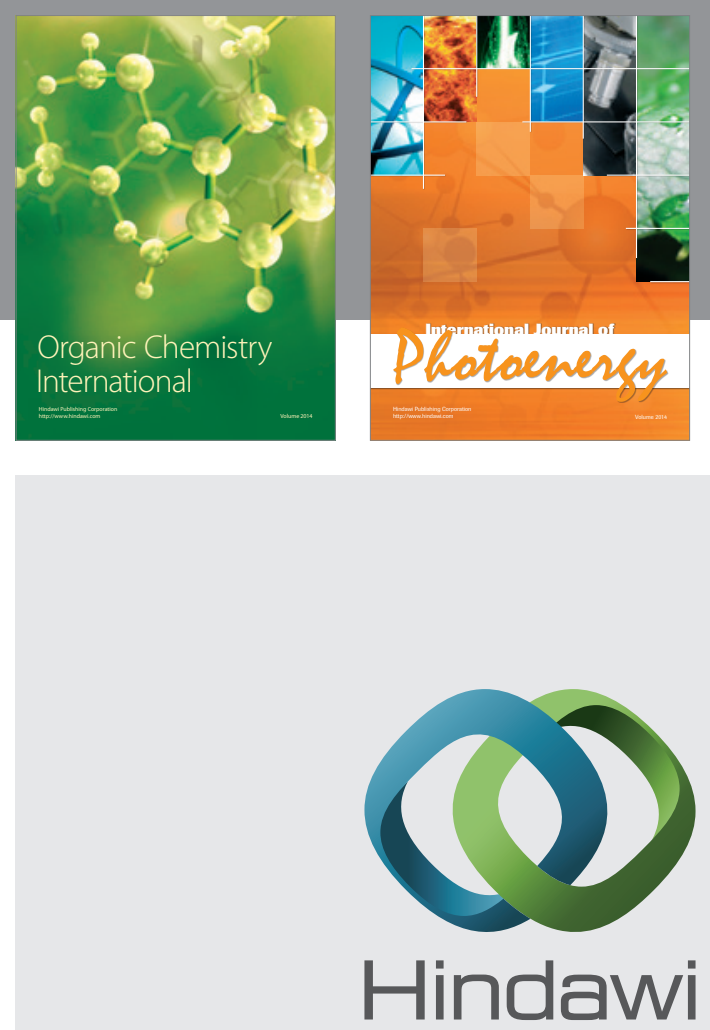

Submit your manuscripts at

http://www.hindawi.com
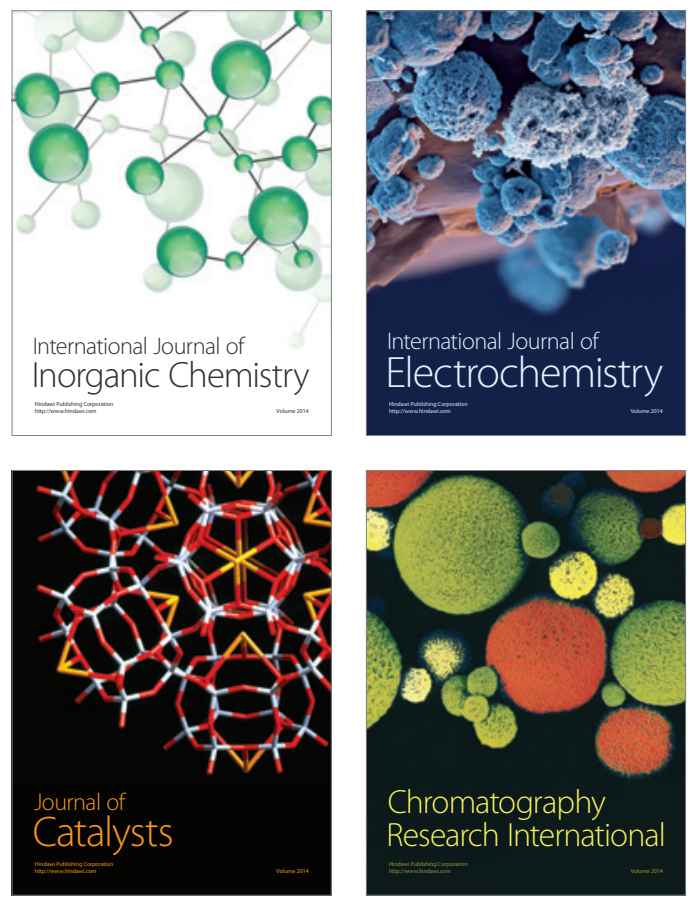
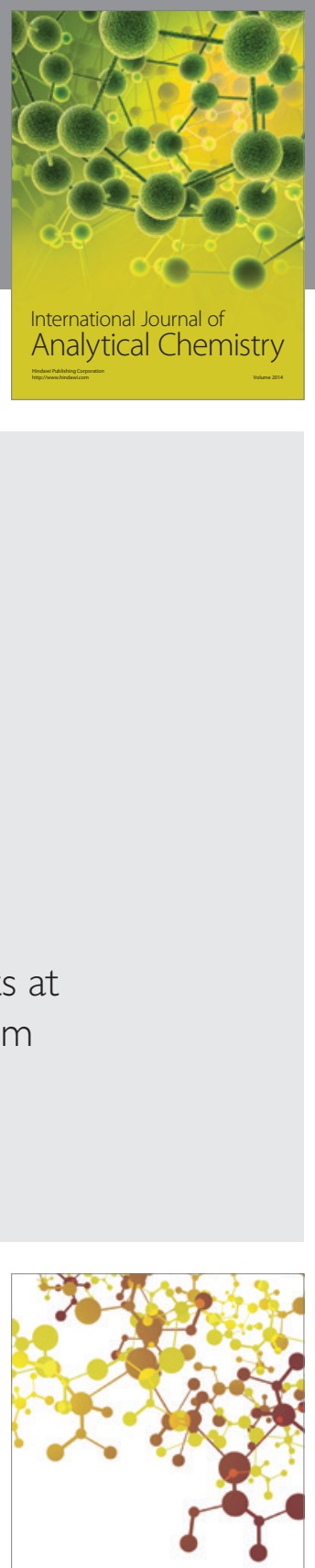

Journal of

Applied Chemistry
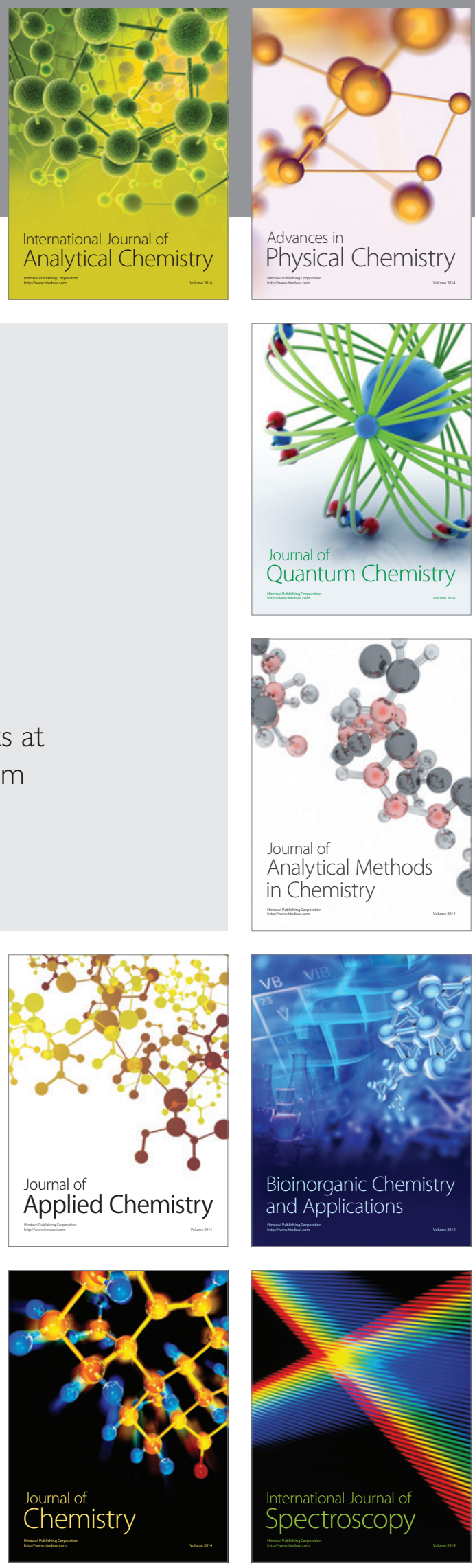